\title{
Quantitative analysis of thermal bridges of structures through infrared thermograms
}

by I. Benko

Dept. of Energy Eng., Budapest Univ. of Technology and Economics, H-1521 Budapest, Muegyetem rkp. 3/D. 208, Hungary.

Phone and fax.: +361-310-0999,

e-mail: benko@eta.enrg.bme.hu or benko@hp.osski.hu

\begin{abstract}
Thermal bridges are those parts or components of a physical structure that have better thermal conductance than their environment i.e. than that of the structure whose parts they are. Thermal bridges cause excess heat loss. This paper presents examples for the analysis of thermal bridges in energy conversion/transportation equipment and building structures. The examples feature the identification of thermal bridge locations and excessive heat loss.
\end{abstract}

\section{Introduction}

There have been two powerful driving forces that have led to the successful analysis of infrared (IR) thermograms (TGs). The first of these has been a rapid rise, in the last decades, in the use and application of histographic image-processing of IR-TGs [2, 3]. Then secondly there has been an increase in the necessity to the mathematical filtering of IR-images $[4,5,6]$.

\section{Generalities}

One can find thermal bridges in the envelope, refractory of energy generation/conversion equipment, in building structures and other mechanical systems that are involved in heat transfer [2]. Theoretical analysis of thermal bridges are well supplemented by the results of IR-TGM that help in finding their location, identifying the boundary conditions and verifying theoretical conclusions. The paper presents examples for the analysis of thermal bridges in building structures (Fig.1 and Fig. 6) and for insulation defects of pipelines (Fig.8 and Fig. 9). The examples feature the identification of thermal bridge locations and excessive heat loss.

\section{Method of statistical examination}

There are two principal methods of the histographic analysis of IR-imagery. The first is the simple methods using the parameters as maximum (max), minimum ( $\min )$, average (avg) values of the temperature field in a selected area (Tab.2). The second one is the extended method applying the parameters as median (med), standard deviation (sdev), skewness (skew) and diagrams of distribution of histogram (D) depending on temperature (Fig.4, Fig.5, and Tab.1.).

\subsection{Histogrqaphic processing}

The basis of the statistical analysis is the histogram of the temperature field (Fig.1 and Fig. 2). Besides essential values characteristic of the histograms (See Chapter 3 ) we apply the number of pixels $\mathrm{N}(\mathrm{t})$ in the examined area (Ncal) and the maximum value on the ordinate of the histogram $\left(F_{\max }\right)$. The relation between $N(t)$ and $n(t)$ at a given temperature $t_{i}$ is

$$
n_{i}(t)=N_{i}(t) / \sum_{i=a}^{b} N_{i}(t)
$$




\subsection{Quantitative parameters}

In histograms which represent temperature fields of digital IR-images, the percentages of pixel numbers $\mathrm{n}(\mathrm{t})$ with the given temperature are plotted against temperatures occurring within the fields (Fig.4).

\subsection{Distribution of histogram}

The distribution curve (D) of the histogram (Fig.5) is the integral of the histogram (Fig.4). (note: median is at $D=0.5$, see Table 1). So the definition of $D_{b}$ is

$$
D_{b}(t)=\sum_{i=a}^{b} n_{i}(t)
$$

\section{Quantitative factors}

In addition to the commonly used histographic parameters two special thermal factors were defined for the IR-testing of thermal performance of concrete slab buildings (Tab.2) which are calculated from the histographic data. They represent the inequality as well as the heat increase of the temperature field of the concrete slab, bringing about the slabjoints.

We can observe two principal types of the different thermal faults on concrete slabs. The first one is the systematic fault on the edges (slab-joints) of a minor area of the entire slab (Fig. 6 and Fig. 7). The second one is the casual fault in the middle part on the minor area of the panel. The efficiency ratio between the heat losses of the "perfect" and the "real" panels is the energy saving factor (ES), showing the energy saving possibility in some cases of correction of the thermal bridges of wall-joints. The inequality factor (IE) is the parameter of casual faults inside the panel.

\subsection{Inequality factor}

The inequality (ie) factor (IE) was defined as the ratio of the maximum temperature difference on the panel $\Delta \mathrm{t}_{\mathrm{ie}}=\mathrm{t}_{\max }-\mathrm{t}_{\min }$ and the average temperature difference between the panel (avg) and the environment (env): $\Delta \mathrm{t}_{\mathrm{env}}=\mathrm{t}_{\mathrm{avg}}-\mathrm{t}_{\mathrm{env}}$. Thus, we have

$$
\mathrm{IE}=\Delta \mathrm{t}_{\mathrm{ie}} / \Delta \mathrm{t}_{\mathrm{env}}
$$

The domain of definition of the IE factor is between $0 \ldots 2$. If $\Delta \mathrm{t}_{\mathrm{ie}}=\Delta \mathrm{t}_{\mathrm{env}}$ then IE=1 and $\mathrm{IE}=2$ if $\Delta \mathrm{t}_{\mathrm{ie}}=2 \Delta \mathrm{t}_{\mathrm{env}}$ (see Tab.2).

\subsection{Energy saving factor}

In the majority of cases, the average temperature of the wall-joint (j) is higher than inside the slab $(\mathrm{sl})$. So the energy saving factor $(\mathrm{ES})$ was defined as the ratio of heat losses of the wall-joint $(\dot{Q} j)$ surface $(A j)$ and that of the "perfect" $(\dot{Q} \mathrm{sl})$ slab $\left(A_{s l}\right)$ :

$$
E S=\frac{\dot{Q}_{j}}{\dot{Q}_{s l}}=\frac{\alpha_{j} A_{j}\left(t_{j}-t_{e n v}\right)}{\alpha_{s l} A_{s l}\left(t_{s l}-t_{e n v}\right)}
$$

Substituting an approach of $\alpha_{j}=\alpha_{s l}$ in Equ. 4 and denoting the area factor by $a=A_{j} / A_{s l}$, further if $\mathrm{t}_{\mathrm{j}}=\mathrm{t}_{\text {avg }}$ and $\mathrm{t}_{\mathrm{sl}}=\mathrm{t}_{\text {min }}$ then we finally have

$$
E S=a \frac{\left(t_{\text {avg }}-t_{\text {env }}\right)}{\left(t_{\text {min }}-t_{\text {env }}\right)}
$$


We present the calculated IE and ES factors for Fig. 1 and Fig. 2 in Table 1 and for Fig. 7 in Table 2, and for Fig. 8 and Fig. 9 in Table 3, where ES*100, \% are the percentage of energy saving.

\section{REFERENCES}

[1] BENKO, I., "Applications of infrared thermogrammetry in thermal engineering" QIRT 92 - Eurotherm Series 27, pp. 343-349, Paris, 1992.

[2] BENKO, I., "Histographic analysis of infrared thermograms in the field of engineering" Workshop '93 on Advanced Infrared Technology and Applications. IROE-CNR, p.33, Capri, 1993.

[3] BENKO, I., "Thermal detection of buildings and environment by INFRAMETRICS devices", Energy and the Environment. Proceedings of the Second Trabzon International Energy and Environment Symposium. Edited by I. Dincer and T.Ayhan, pp. 205-208 Begell House, Inc. New York, 1999.

[4] BENKO, I., "Infra-red image filtering as a tool of temperature-field analysis", Proceedings of TEMPMEKO '99. Edited by J.F. Dubbeldam and M.J. de Groot. NMi Van Swinden Laboratorium, , Vol.2, pp. 657-662, Delft, 1999.

[5] BENKO, I., "Analysis of infrared thermograms through mathematical filtering", Gépészet 2000, Proceedings of Second Conference on Mechanical Engineering, edited by K.Molnár, Gy. Ziaja, G. Vörös, Springer Medical Publishers, Vol.2 pp. 350355, Budapest, 2000.

[6] BENKO, I., "Mathematical filtering of infrared images for integrated-circuit techniques" The Imaging Science Journal 48, pp.45-50, 2000.

[7] BENKO, I., "Infrared testing of thermal performance of concrete slab buildings", $12^{\text {th }}$ Int. Conf. on Thermal Engineering and Thermogrammetry, Budapest, Hungary, 2001, pp. 161-166.

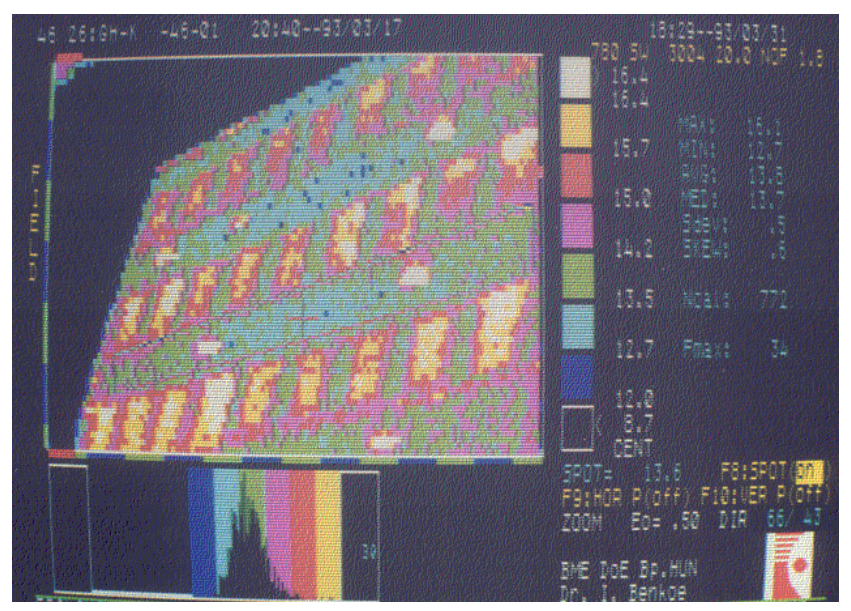

Fig. 1. Thermogram of a prefabricated slab building wall (No.1.) with a histogram of a selected minor area below the windows (see Table 1.) 


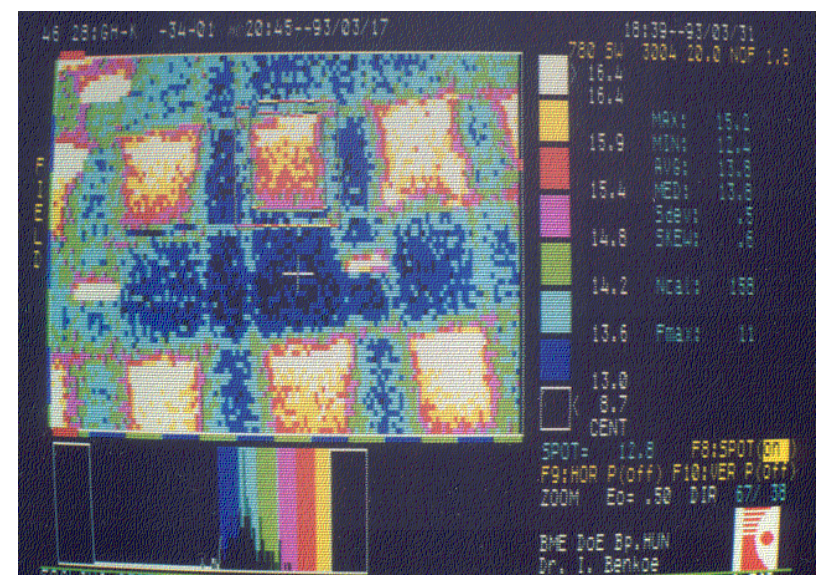

Fig. 2. Histogram of an area around the window on Fig.1 (see Table 1)

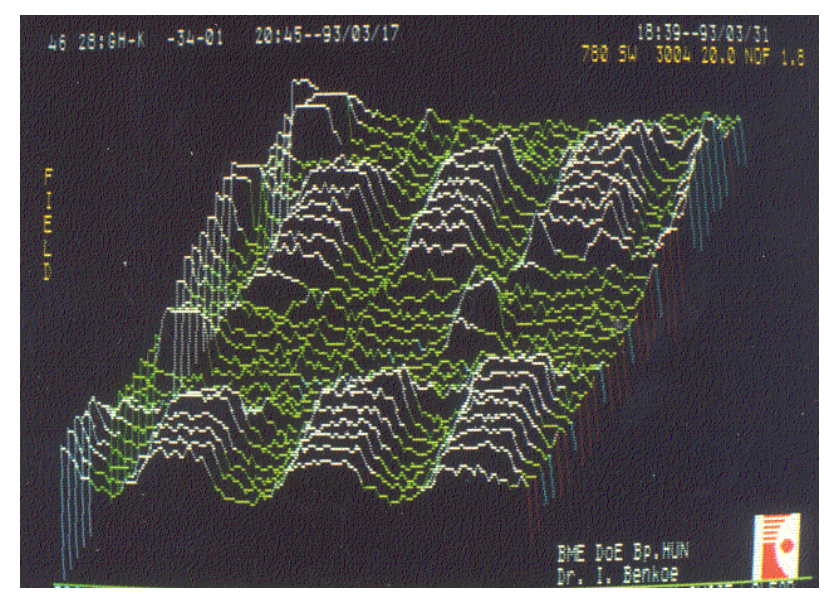

Fig. 3. Relief-thermogram of Fig. 2 shows the temperature distribution on wall No.1

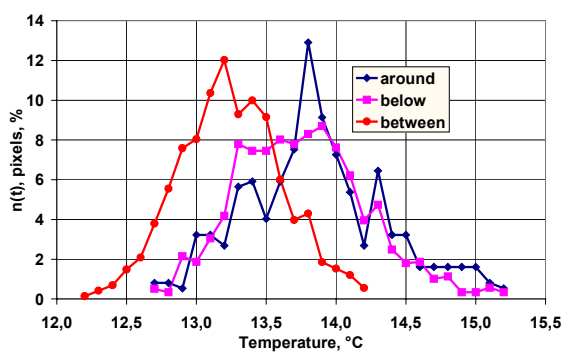

Fig. 4. Comparison of the histograms of a building envelope (Fig.1) around, below, and between the windows (see Tab. 1.)

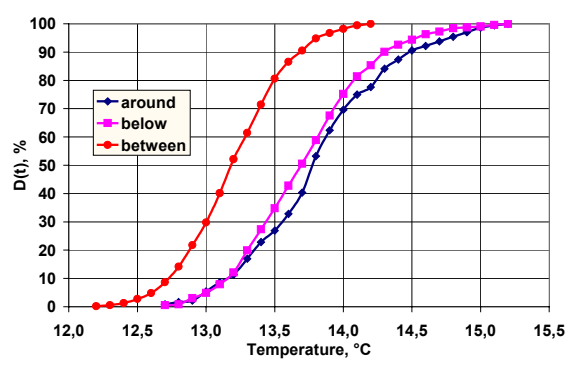

Fig. 5. Distributions of histograms of a building envelope around, below, and between the windows (see Fig. 4) 
Table 1: Collected data of the extended histographic analysis of Fig.1 and Fig.2

\begin{tabular}{|c|c|c|c|c|c|c|c|c|c|}
\hline \multicolumn{3}{|c|}{ Topic } & \multicolumn{5}{|c|}{ Characteristics of the histogram, ${ }^{\circ} \mathrm{C}$} & \multicolumn{2}{|c|}{$\begin{array}{c}\text { Quantitative } \\
\text { factors }\end{array}$} \\
\hline & a & site & $\max / \min$ & avg. & med & Sdev & Skew & $\mathrm{IE}$ & ES \\
\hline \multirow{3}{*}{$\begin{array}{l}\text { Windows of } \\
\text { wall No. } 1 \\
t_{\text {env }}=0^{\circ} \mathrm{C}\end{array}$} & 0.3 & around & $15 / 2 / 12.4$ & 13.8 & 13.8 & 0.5 & 0.6 & 0.20 & 0.33 \\
\hline & 0.4 & below & $16.1 / 12.7$ & 13.8 & 13.7 & 0.5 & 0.6 & 0.25 & 0.43 \\
\hline & 0.2 & between & $14.8 / 12.2$ & 13.3 & 13.2 & 0.4 & 0.4 & 0.19 & 0.22 \\
\hline
\end{tabular}

Table 2:. Data of the simple histographic analysis of Fig.7

\begin{tabular}{|c|c|c|c|c|c|c|c|}
\hline \multirow{2}{*}{$\begin{array}{c}\text { End-wall } \\
\text { No. }\end{array}$} & \multirow{2}{*}{$\begin{array}{l}\text { Floor } \\
\text { No. }\end{array}$} & \multicolumn{3}{|c|}{$\begin{array}{c}\text { Values of temperature } \\
\text { distribution, }{ }^{\circ} \mathrm{C} \\
\end{array}$} & \multicolumn{2}{|c|}{$\begin{array}{l}\text { Quantitative } \\
\text { factors }\end{array}$} & \multirow{2}{*}{$\begin{array}{l}\text { Spot, } \\
{ }^{\circ} \mathrm{C}\end{array}$} \\
\hline & & min. & avg. & max. & $\mathrm{IE}$ & ES & \\
\hline \multirow{4}{*}{$\begin{array}{l}\text { No. } 2 . \\
\text { East-side } \\
t_{\text {env }}=4{ }^{\circ} \mathrm{C} \\
a=0.2\end{array}$} & 10. & 7.7 & 11 & 15.5 & 1.1 & 0.38 & \\
\hline & 8. & 8.7 & 12 & 15.9 & 0.9 & 0.34 & \\
\hline & 7. & 8.0 & 11.9 & 15.9 & 1.0 & 0.39 & $15.2 / 10.5$ \\
\hline & 10.-7. & 7.3 & 11.6 & 15.9 & 1.13 & 0.46 & \\
\hline
\end{tabular}

Table 3:. Insulation defects of district heating lines and pipeline supports $(a=0.2)$ at $t_{e n v}=-1{ }^{\circ} \mathrm{C}$

\begin{tabular}{|l|c|c|c|c|c|c|}
\hline \multirow{2}{*}{ Insulation defects } & \multicolumn{3}{|c|}{$\begin{array}{c}\text { Values of temperature } \\
\text { distribution, }{ }^{\circ} \mathrm{C}\end{array}$} & \multicolumn{2}{c|}{$\begin{array}{c}\text { Quantitative } \\
\text { factors }\end{array}$} & \multirow{2}{*}{$\begin{array}{c}\text { Spot, } \\
\end{array}$} \\
\cline { 2 - 7 } & min. & avg. & max. & IE & ES & ${ }^{\circ} \mathrm{C}$ \\
\hline Pipeline (Fig.8) & 7.3 & 9.9 & 21.3 & 1.28 & 0.26 & 19.8 \\
\hline Pipeline supports (Fig.9) & 4.0 & 6.1 & 18.5 & 2.04 & 0.28 & 14.9 \\
\hline
\end{tabular}

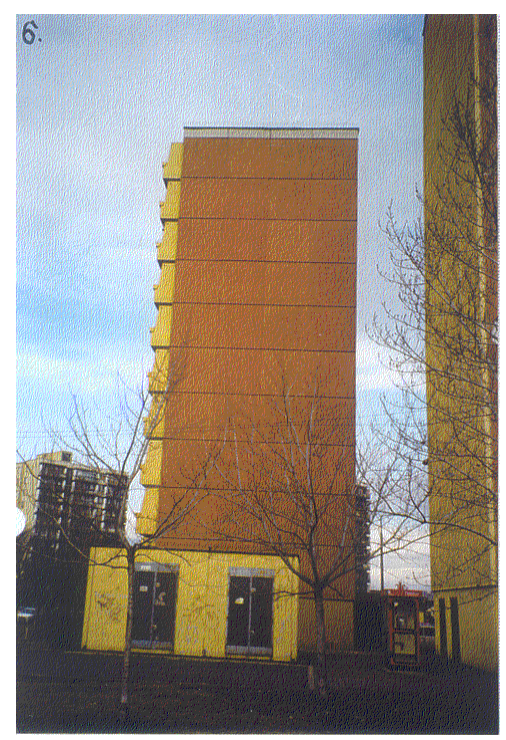

a.

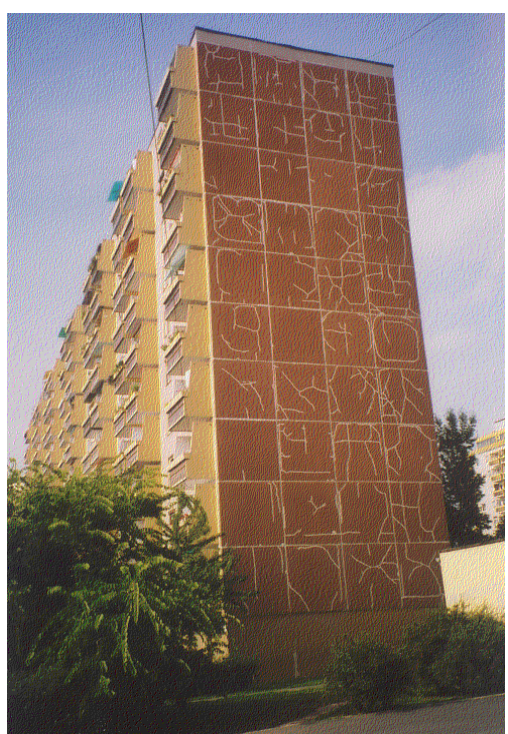

b.

Fig. 6. Photos of the slab joints of a building structure (No.2) oriented to East before (a.) and after (b.) the repairing of systematic faults (of first type) on the slab-edges 


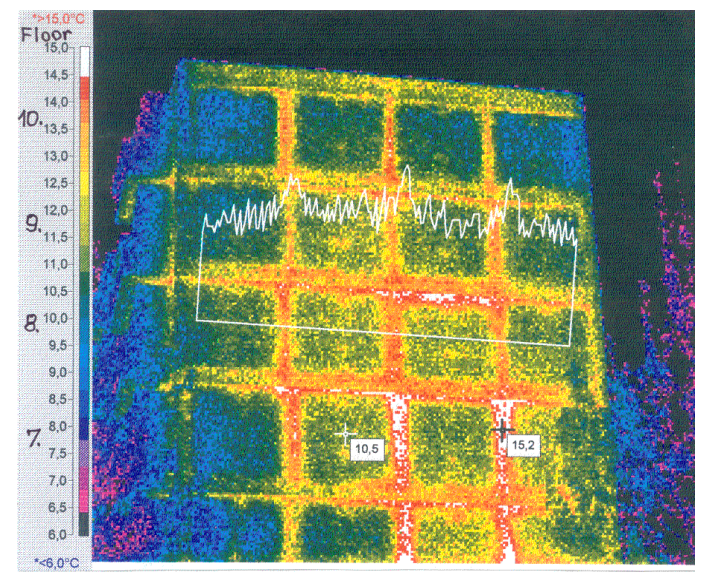

Fig. 7. Thermogram and line-thermogram of an end-wall (No.2) of a building structure (Fig 6.a) before the repair of the slab-edges

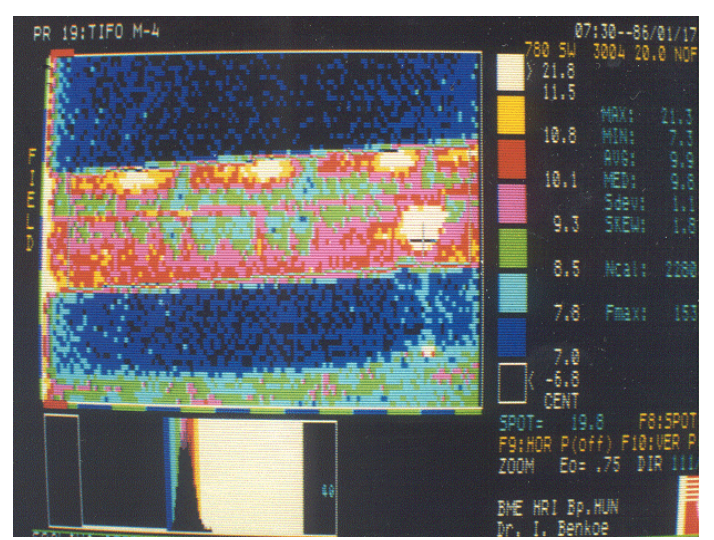

Fig. 8. IR thermogram of insulation defects of a district heating line

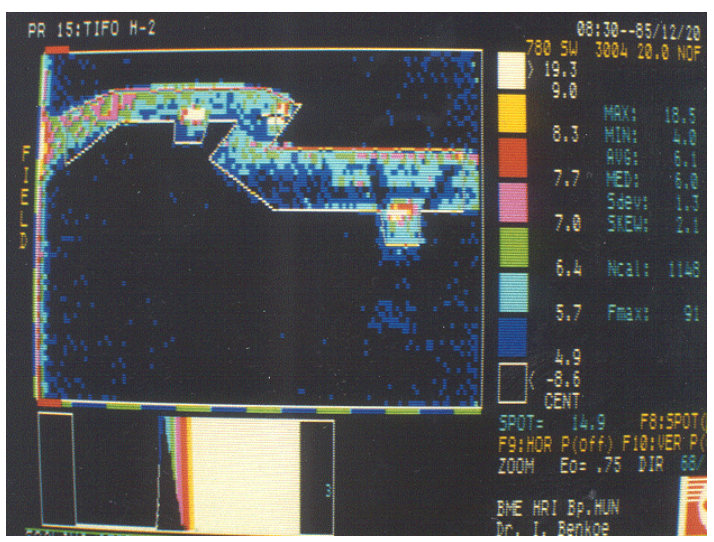

Fig. 9. Insulation defects of two pipeline supports 